\title{
ESTRATÉGIAS DIDÁTICAS NO ENSINO DE QUÍMICA
}

\author{
Fábio Merçon ${ }^{1}$ \\ Marcelo Pinheiro de Souza \\ Carlos Magno Sady Valadares ${ }^{3}$ \\ Jorge Alberto Saboya Pereira4 \\ Josineide Alves da Silva ${ }^{5}$ \\ Raimundo Elito Conceição ${ }^{6}$
}

CAp-UERJ

\section{RESUMO:}

Apesar de estar constantemente presente no dia-a-dia, a química é uma disciplina considerada complexa e desnecessária pela maioria dos alunos da educação básica. Visando reverter este quadro e promover um ensino crítico, contextualizado e motivador, educadores e pesquisadores vêm destacando a importância de se promover o aprendizado, mediante o emprego de recursos didáticos associados com a experimentação e o uso de softwares educacionais. No presente trabalho, foi feita uma avaliação das atividades desenvolvidas pela equipe de química do CAp/UERJ, baseada no emprego destes recursos didáticos. Experimentos e recursos de informática demonstraram-se extremamente importantes no processo de ensino-aprendizagem, com destaque para seu efeito motivador, constatado pelo aumento da participação dos alunos nas atividades. Além disto, também se verificou o favorecimento da construção do conhecimento, da aprendizagem colaborativa e o estímulo do caráter investigativo e da tomada de decisão.

Palavras-chave: ensino de química - experimento - softwares educacionais

\begin{abstract}
:
Although it is presented in quotidian, chemistry is considered complex and unnecessary for most of the students of the basic education. To revert this situation and promote a critical, contextualizated and motivator teaching, recently researches are pointing the importance of promoting the learning by the use of didactic resources associated with the experimentation and the use of education softwares. In the present work it was made an evaluation of the activities developed in CAp/UERJ based in the use of didactic resources. Experiments and computer science resources demonstrated being an important in teaching-learning process, with a motivator effect, verified by the increase in students participation in the activities.
\end{abstract}

KEY WORDS: Chemistry teaching - experiment - educational softwares 
e-Mosaicos - Revista Multidisciplinar de Ensino, Pesquisa, Extensão e Cultura do Instituto de Aplicação Fernando Rodrigues da Silveira (CAp-UERJ)

ANO 1 - V. 1 - N. 1 - JUNHO 2012 - ISSN: 2316-9303

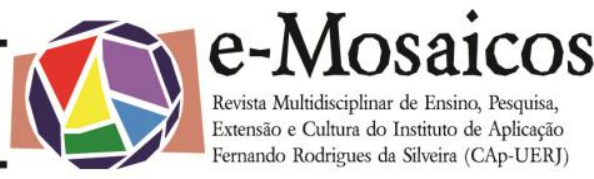

\section{INTRODUÇÃO}

Nas últimas décadas, a busca por novas metodologias de ensino de química tem sido o campo de estudos de pesquisadores e professores envolvidos com a educação em química. As tradicionais metodologias de ensino, baseadas no modelo didático de transmissão-recepção e fundamentadas na memorização de regras, nomes e fórmulas, acabam por desmotivar os alunos e distanciar a ciência ensinada nas escolas do dia-adia da sociedade, gerando espaço para um questionamento, por parte dos alunos, sobre os reais objetivos do estudo da química.

A observação que, geralmente, os currículos tradicionais têm enfatizado apenas aspectos conceituais da química, transformando a cultura química escolar em algo completamente descolado de suas origens científicas e de qualquer contexto social ou tecnológico, foi apontada por Mortimer et al. (2000). Estes autores verificaram que esses currículos apresentam um número excessivo de conceitos (definições), cuja inter-relação é dificilmente percebida pelos alunos. Deste modo, a química se torna uma ciência totalmente desvinculada da realidade, que requer mais memória do que 0 estabelecimento das relações. Logo, os conceitos passam a ser utilizados de forma mecânica na resolução de problemas e exercícios. Segundo estes autores,

o ensino de química tradicional é fruto, na maioria das vezes, de um processo histórico de repetição de fórmulas que são bem sucedidas do ponto de vista didático - fazer com que o aluno aprenda alguns procedimentos relacionados à Química, transformando a disciplina num manejo de pequenos rituais. (Mortimer et al., 2000)
A repetição acrítica de fórmulas didáticas, além de distanciar a química escolar da ciência química e de suas aplicações na sociedade, acaba por contribuir para transformar o processo de ensino-aprendizagem em algo desinteressante e sem sentido, que apenas exige esforço de memória. Desta forma, constata-se a incapacidade desta disciplina em inserir o aluno na realidade em que vive, não colaborando para a formação de um cidadão capaz de opinar sobre temas relevantes do seu cotidiano. Assim, o ensino de química desvincula-se de uma das finalidades da educação básica, a saber:

A educação básica tem por finalidades desenvolver o educando, assegurar-lhe a formação comum indispensável para o exercício da cidadania e fornecer-Ihe meios para progredir no trabalho e em estudos posteriores. (BRASIL, CONGRESSO NACIONAL, 1996, art. 22)

Com o intuito de inserir a química neste processo de cidadania, motivando os alunos e reorganizando os conteúdos programáticos, diversas metodologias de ensino foram propostas e desenvolvidas.

Dentre as diversas estratégias didáticas propostas para reverter este quadro, duas merecem destaque: atividades experimentais e softwares educacionais. Tendo em vista que a química se desenvolveu como uma ciência experimental, o laboratório talvez seja um dos espaços mais antigos para o ensino desta ciência. Por sua vez, somente nas últimas décadas é que o computador entrou em nossos lares e nas escolas. Entretanto, um ponto em comum destas duas metodologias está nos resultados positivos que rotineiramente são apresentados na literatura especializada. 
e-Mosaicos - Revista Multidisciplinar de Ensino, Pesquisa, Extensão e Cultura do Instituto de Aplicação Fernando Rodrigues da Silveira (CAp-UERJ) ANO 1 - V. 1 - N. 1 - JUNHO 2012 - ISSN: 2316-9303

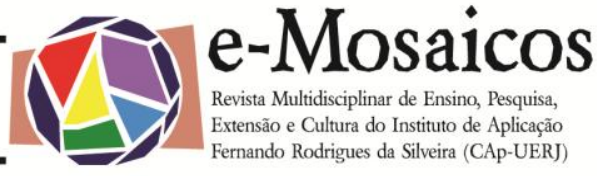

Diante deste quadro, a equipe de química do Instituto de Aplicação Fernando Rodrigues da Silveira (CAp/UERJ) tem investido recursos na implementação de atividades didáticas envolvendo estes dois tipos de recursos. Em 1999, com a mudança do colégio para a sede atual e a inauguração dos laboratórios de ciências, teve início o projeto de aulas práticas de química. Desde então, os alunos do ensino médio e do nono ano do ensino fundamental têm participado de aulas periódicas no laboratório de química. De forma semelhante, com a implantação do laboratório de informática da escola em 2003, a equipe de química começou a ministrar aulas neste espaço.

Diante dos resultados alcançados com essas atividades, o presente trabalho teve como objetivo apresentar este projeto, bem como discutir sua inserção no processo pedagógico do colégio e reportar os resultados de aceitação das aulas práticas de química entre os alunos do CAp.

\section{REVISÃo BIBLIOGRÁFICA}

\section{A experimentação no ensino de quími- ca}

Um ponto comum entre os professores de química é que a atividade experimental tem uma função motivadora no processo de ensino-aprendizagem. Giordan (1999) constatou que este fato costuma ser justificado pelo aumento do interesse dos alunos, que, em consequência de seu envolvimento com o experimento, acabam por ter um aumento em sua capacidade de aprendizado.

Por outro lado, deve-se evitar uma visão simplista de que a mera inclusão de aulas práticas é uma alternativa para melhorar o ensino (Almeida e Barreto Filho, 2001). Segundo Schnetzler (2002), este tipo de pensamento é consequência do predomínio de concepções empiristas e indutivistas entre a maioria dos professores, as quais decorrem da ausência da discussão epistemológica durante a formação inicial e continuada destes profissionais em educação.

Nos últimos anos, o emprego de aulas práticas tem sido alvo de inúmeros questionamentos e reflexões, por parte dos pesquisadores em ensino de ciências. É um fato comum a constatação de que o experimento exerce um papel motivador nos alunos e que uma significativa parcela de professores acredita que a mera inclusão de atividades práticas é uma alternativa para melhorar 0 ensino. Lôbo e Moradillo (2003) observaram que esta visão simplista decorre do predomínio de concepções empiristas e indutivistas na formação inicial destes educadores.

A principal crítica ao empirismoindutivismo está na crença de que uma observação neutra e desprovida de teorias ou ideias prévias é o ponto de partida para a construção do conhecimento científico. Esta visão remonta a discussão sobre a função da experimentação na construção do conhecimento científico. Giordan (1999) constatou a importância dos trabalhos de pensadores, como Bacon, Descartes e Galileu, na constituição da ciência moderna e na estruturação de um método científico que deu ao empirismo posição de destaque. Por sua vez, estas concepções também nortearam os ideais positivistas de Comte, que influenciam as práticas pedagógicas até os dias de hoje.

Silva e Zanon (2000) apontaram a importância que o experimento pode assumir no ensino de química contemporâneo, no qual os aspectos evidenciados com o experimento e as ideias iniciais do aluno devem ser explorados por intermédio da mediação do professor. Estas autoras citam que: 
e-Mosaicos - Revista Multidisciplinar de Ensino, Pesquisa, Extensão e Cultura do Instituto de Aplicação Fernando Rodrigues da Silveira (CAp-UERJ) ANO 1 - V. 1 - N. 1 - JUNHO 2012 - ISSN: 2316-9303

Ao valorizar a visão da experimentação como uma estratégia dinâmica e interativa que privilegia a negociação de significados de saberes e que favorece a construção de conhecimentos a partir da exploração de contextos (reais ou criados), queremos estimular a atividade cognitiva e o desenvolvimento de potencialidades do aluno para a vida na sociedade/ambiente.

Silva e Zanon (2000) citam que o positivismo foi cunhado para se opor às concepções metafísicas e teológicas, de forma que as experiências sensoriais não poderiam ser a base para o conhecimento e somente seria considerado o conhecimento que advém de fenômenos observáveis empiricamente. Esta linha de pensamento validou o método científico indutivo, como o único caminho para o conhecimento científico e, consequentemente, para ensinar ciências. Assim, do paradigma positivista originou-se a concepção epistemológica que prevaleceu por todo o século XX, fundamentada no modelo da racionalidade técnica. Segundo este modelo, os problemas surgidos na prática são resolvidos aplicando-se as teorias científicas. Este é um modelo que valoriza o conhecimento científico em detrimento da prática pedagógica. Como consequência do paradigma positivista, estas autoras atribuem a prevalência no âmbito escolar de uma

visão dogmática da ciência, centrada no verdadeiro, no definitivo, no certo, na única resposta verdadeira e correta para qualquer tipo de questão ou problema que se apresente, segundo a qual o científico é algo taxativo, inquestionável e exato, a ser transmitido de forma pronta e cumulativa através da escola. (Silva e Zanon, 2000)

A apresentação de uma ciência neutra, empírica, quantitativa e verdadeira contribui para formar um aluno isento/neutro, que é apenas um simples reprodutor do que lhe é apresentado. Apesar de sua grande abrangência, já nas primeiras décadas do século XX, o empirismo-indutivismo foi duramente criticado por filósofos da ciência, como Bachelard, Popper, Kuhn e Lakatos, ao defenderem os ideais de cunho racionalista e construtivista. Nesta nova perspectiva, " 0 conhecimento é obtido a partir de hipóteses e teorias que passam a orientar a observação dos fenômenos, de forma que não existe observação neutra, desprovida de intencionalidade"(Lôbo e Moradillo, 2003).

Segundo Schnetzler (2002), diante do paradigma empirista-indutivista, os movimentos de reforma curricular, ocorridos principalmente nos Estados Unidos e na Inglaterra, na década de 1960 , enfatizaram o uso do laboratório para introduzir e explorar problemas.

Ao final da década de 1970, os resultados pouco promissores alcançados por estes projetos de ensino direcionaram o desenvolvimento de pesquisas com ênfase nos processos de aprendizagem. Desta forma:

A investigação passou a ser mais qualitativa, com ênfase em estudo de casos, nos quais observações em sala de aula, realização de entrevistas, elaboração de textos e desenhos por parte dos alunos passaram a ser os instrumentos mais utilizados para a coleta de dados. Além disso, os pesquisadores passaram a 
e-Mosaicos - Revista Multidisciplinar de Ensino, Pesquisa, Extensão e Cultura do Instituto de Aplicação Fernando Rodrigues da Silveira (CAp-UERJ) ANO 1 - V. 1 - N. 1 - JUNHO 2012 - ISSN: 2316-9303

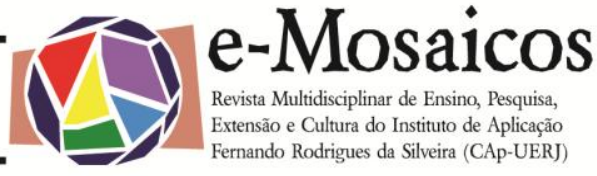

se fundamentar em contribuições da psicologia cognitivista, concebendo a aprendizagem como evolução, reorganização ou mudança das concepções dos alunos. (Schnetzler, 2002)

Em consequência destas ações, os trabalhos desenvolvidos a partir da década de 90 passaram a adotar referenciais epistemológicos mais racionalistas e contemporâneos de ciência, incorporando a dimensão sóciointeracionista à análise do processo de ensino-aprendizagem (Schnetzler, 2002).

Segundo Mortimer e Carvalho (1996), nesta época o processo de ensino deixou de ser uma simples transposição do trabalho dos cientistas e o desenvolvimento cognitivo do ser humano passou a ser um parâmetro fundamental nos projetos pedagógicos.

Mortimer et al. (2000) citam que, além do desenvolvimento de habilidades específicas, como controlar variáveis, organizar dados em tabelas e construir gráficos, um experimento pode cumprir também o papel de apresentar o pensamento químico, onde teoria e realidade estão em constante interlocução. $\mathrm{O}$ aluno pode ser levado a formular hipóteses, desenvolver formas de testá-las e modificá-las de acordo com os resultados.

Dentro desta linha de pensamento, Silva e Zanon (2000) constataram que, até nos dias de hoje, o emprego de aulas práticas se restringem a uma sequência de procedimentos presentes em um roteiro e, geralmente, culminam com a elaboração de um relatório que prioriza a descrição do experimento, em detrimento de explicações e significações no nível teórico-conceitual. Estas explicações envolvem linguagens e modelos próprios das ciências e são impossíveis de serem desenvolvidas pelos alunos, sem o auxílio pedagógico do professor.

As críticas à visão empirista-indutivista de ciência têm proporcionado o desenvolvimento de propostas de ensino norteadas por uma observação dependente da teoria. Machado (1999) ponderou que a observação acarreta a construção discursiva, em detrimento de uma construção empírica, dos conceitos químicos. Neste âmbito, as préconcepções do observador norteiam suas percepções e os condicionantes pessoais é que fazem com que os alunos construam suas relações a partir da observação de um determinado fenômeno químico.

Partindo-se do pressuposto de que, na construção do conhecimento científico é improvável uma observação desprovida de hipóteses e teorias prévias, na sala de aula esse mesmo conhecimento dificilmente é construído pelos alunos através da simples observação de experimentos. Neste momento, a presença do professor é fundamental, pois cabe a ele introduzir os conceitos científicos e mediar o acesso dos alunos aos mesmos.

\section{A informática aplicada ao ensino de química}

A aplicação das tecnologias de informação e comunicação nas escolas tem-se mostrado uma metodologia importante na formação dos alunos, contribuindo para a "pedagogia de construtivismo" (Silva, 1998) e minimizando a ideia de que o conhecimento só é adquirido no ambiente de sala de aula, através de informações que podem ser analisadas e agrupadas para uma posterior construção de conhecimento. A informática não deve ser vista como uma disciplina a ser adicionada à grade curricular, mas como um componente transdisciplinar, que pode servir de apoio e dinamizar o aprendizado 
e-Mosaicos - Revista Multidisciplinar de Ensino, Pesquisa, Extensão e Cultura do Instituto de Aplicação Fernando Rodrigues da Silveira (CAp-UERJ) ANO 1 - V. 1 - N. 1 - JUNHO 2012 - ISSN: 2316-9303

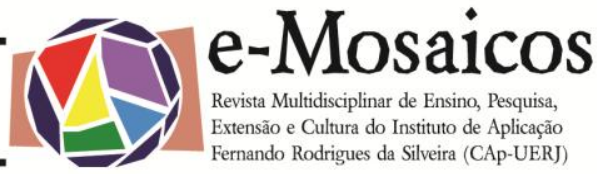

em todas as áreas e componentes curriculares.

Eichler e Del Pino (2000a) relataram que, na década de 80 , foram iniciadas experiências de informatização das escolas de ensino básico, com investimentos na formação de recursos humanos e aquisição de equipamentos visando a implementação e o uso de laboratórios de informática. Hoje em dia, muitos pesquisadores entendem que o computador deve ser visto como mais um recurso didático à disposição do professor. As múltiplas possibilidades de uso podem suscitar profundas transformações na prática docente e nos processos de aprendizagem. Estes autores apontam a contribuição do computador na representação de modelos da ciência, de forma que as imagens estáticas e bidimensionais dos livros ganham uma nova dimensão e movimento. Assim, os processos deixam de ser descritos para serem simulados, proporcionando ao estudante o controle dos parâmetros e de variáveis de estudo.

Ao analisarem a importância do computador na vida cotidiana, Meleiro e Giordan (1999) observaram que atualmente "o analfabeto não é só aquele que não domina a leitura, a escrita e a oralidade (analfabetismo tradicional), mas também aquele que não detém os códigos que lhe permitam dominar a leitura da imagem e a utilização de recursos informáticos."

Infelizmente, na grande maioria das escolas, o principal foco da educação computacional tem sido relacionado com o processamento de palavras, ou gerenciamento de informações, sendo mínima a contribuição no sentido de relacionar a informática e seu papel na sociedade. Neste âmbito, é importante o desenvolvimento de softwares e outros recursos adequados aos estudantes e eficientes como meio facilitador dos proces- sos de ensino, comunicação e aprendizagem.

Ao se analisar o emprego da informática no ensino de química, percebe-se que a utilização de recursos computacionais pode contribuir no processo educacional e na tentativa de contextualizar a teoria e a prática no ensino desta disciplina. Dallacosta et al. (1998) constataram que os computadores têm revolucionado a educação em química. Segundo estes autores, os recursos computacionais atraem e motivam os estudantes, aumentam a capacidade de compreensão, favorecem a visualização de conteúdos abstratos e de reações químicas potencialmente perigosas e seu uso pode ser estendido ao laboratório. Apesar destes fatores, é importante frisar que o computador não deve ser encarado como um substituto das atividades experimentais, tão comuns no ensino de química, pois existem habilidades e procedimentos do trabalho científico que só podem ser proporcionadas pela atividade de laboratório.

Eichler e Del Pino (1999) defendem a inclusão das atividades de aprendizagem em ciências mediadas por computador, diante de uma proposta de ensino para formar a cidadania dos alunos. Estes autores analisaram a importância de ferramentas de busca em jornais e revistas on-line, como facilitadoras na divulgação, circulação e utilização de matérias jornalísticas, que podem ser utilizadas em atividades voltadas para a resolução de problemas, que valorizam a reflexão, a capacidade de tomada de decisão e a socialização das atividades.

A importância da hipermídia no ensino de modelos atômicos foi avaliada por Meleiro e Giordan (1999), que destacaram as representações digitais construídas por meio de computação gráfica e a possibilidade de simulações, transformando a tela do compu- 
e-Mosaicos - Revista Multidisciplinar de Ensino, Pesquisa, Extensão e Cultura do Instituto de Aplicação Fernando Rodrigues da Silveira (CAp-UERJ) ANO 1 - V. 1 - N. 1 - JUNHO 2012 - ISSN: 2316-9303

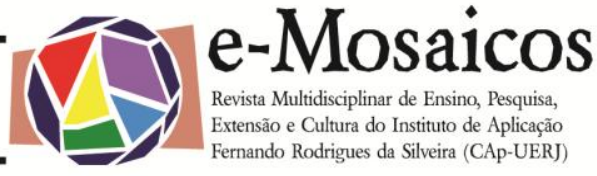

tador em um "laboratório experimental" no qual são "atualizadas as estilizações de fenômenos físicos e químicos, com o intuito de representar como a natureza se comporta sob determinadas condições". Estes autores destacaram a importância da representação tridimensional de moléculas, visto que a disposição espacial dos átomos é fundamental para a compreensão de muitas propriedades moleculares.

Giordan e Mello (2000) analisaram a contribuição de serviços disponíveis na Internet de atendimento a dúvidas dos estudantes e constataram que a Internet é um ambiente capaz de instaurar situações dialogadas de ensino-aprenizagem, sem que aluno e professor compartilhem do mesmo espaço físico. Além de dispor de um extenso banco de dados, a Internet propicia um meio de comunicação e informação que torna os ambientes de aprendizagens plurais e abertos, ampliando as possibilidades de aprendizagem e o espaço de atuação dos professores. Por fim, estes autores reiteram a importância do diálogo por correio eletrônico, pois a elaboração escrita de uma dúvida é um processo de problematização.

Brito (2001) observou que os recursos computacionais podem ampliar o conceito de aula, propiciando a criação de novas pontes cognitivas. Além disto, em um ambiente multimediatizado a integração de diferentes metodologias pode proporcionar uma aprendizagem mais dinâmica e agradável, com grande potencial para uma aprendizagem significativa.

Michel et al. (2004) realizaram uma revisão de softwares e sites educacionais de química. Estas autoras apontaram a importância dos recursos de informática como ferramentas de ensino, visando uma integração na qual a tecnologia deve se adequar à abordagem educacional. A partir de uma análise de 17 sites em português, foi possível concluir que as ferramentas da informática podem contribuir no processo de construção do conhecimento e que cabe aos professores incorporá-las como recurso em sua prática docente.

Segundo Eichler e Del Pino (1988), a abordagem cognitivista se manifesta nos softwares que possuem técnicas de simulação, modelagem e jogo. Nesta abordagem, a construção do conhecimento é contínua e caracterizada pela formação de novas estruturas mentais que não existiam no indivíduo anteriormente. $\mathrm{O}$ aluno aprende por si próprio a conquistar as verdades, informações, modelos, através da aquisição de instrumental lógico-racional. $\mathrm{O}$ objeto é assimilado e associado a esquemas mentais, baseandose no ensaio-erro, na pesquisa, na investigação e na solução de problemas. Por sua vez, Giordan (1999) relatou a importância, no processo de aprendizagem, de ambientes que propiciem o desenvolvimento de simulações, ao subsidiar o processo de elaboração de modelos mentais. Este autor acredita que "as simulações computacionais podem ser orquestradamente articuladas com atividades de ensino, sendo portanto mais um instrumento de mediação entre o sujeito, seu mundo e o conhecimento científico". Vieira (2001), também destacou os softwares de simulação e modelagem, por permitirem uma interatividade maior entre usuário e o conhecimento, o que pode favorecer a aprendizagem significativa dos conteúdos químicos. Os softwares de simulação possibilitam destacar aspectos específicos do conteúdo abordado e orientar a tomada de decisões em experimentos, situações que favorecem muito a compreensão dos conceitos da disciplina. Já os softwares de modelagem exploram uma enorme potencialidade do computador, que é a capacidade de construção de modelos pelos alunos, po- 
e-Mosaicos - Revista Multidisciplinar de Ensino, Pesquisa, Extensão e Cultura do Instituto de Aplicação Fernando Rodrigues da Silveira (CAp-UERJ) ANO 1 - V. 1 - N. 1 - JUNHO 2012 - ISSN: 2316-9303

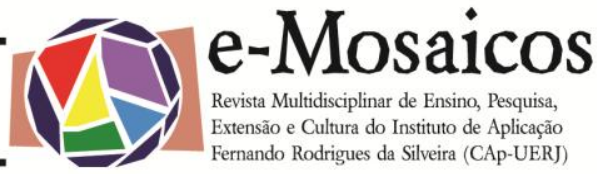

dendo-se criar modelos diferentes dos ensinados em aula, e que podem funcionar da mesma forma na explicação de fenômenos.

No processo educativo, a escolha de um software deve satisfazer os objetivos do professor e as características dos estudantes, de forma a possibilitar várias possibilidades de aprendizagem. Eichler e Del Pino (2000b) constataram que um software não funciona automaticamente como desencadeador do processo de aprendizagem, e, para que ele seja efetivo, deve haver uma integração com o currículo e com as atividades de sala de aula. Esta linha de pensamento se faz presente na análise de outros pesquisadores, que destacam a importância do professor no planejamento e desenvolvimento de estratégias didáticas que contemplem estes softwares em sua prática docente, propiciando maior liberdade para a instauração do processo de construção do conhecimento (Meleiro e Giordan, 1999; Michel et al., 2004; Souza et al., 2004).

\section{Objetivos} objetivos:

Este trabalho apresenta os seguintes

- Apresentar as atividades didáticas desenvolvidas nos laboratórios de química e de informática pela equipe de química do CAp/UERJ.

- Avaliar os resultados destas atividades a partir da análise de questionários respondidos pelos alunos do CAp/UERJ.

- Discutir a importância do emprego de atividades didáticas que envolvem a experimentação e softwares educacionais no ensino de química.

\section{Metodologia}

Desde sua implantação, os projetos de aulas práticas e de informática têm sido permanentemente avaliados e discutidos na instituição. Desta forma, já foram feitas diversas mudanças e adaptações didáticas. Um dos principais instrumentos de avaliação foi a opinião dos alunos do CAp. Além dos relatos e observações colhidos ao longo dos anos, os estudantes também puderam se expressar através de questionários.

No projeto de aulas práticas, ao final de três anos letivos, foi aplicado um questionário, respondido por 249, 146 e 168 alunos, respectivamente. Por sua vez, como o projeto de informática é mais recente, em apenas um ano letivo foi aplicado um questionário, após uma atividade desenvolvida pelas turmas da segunda série do ensino médio, respondido por 96 alunos.

\section{Resultados e Discussão}

\section{Atividades desenvolvidas no CAp/UERJ}

Dois pontos importantes no desenvolvimento das atividades nos dois espaços (laboratórios de química e de informática) são: correlação com os conteúdos desenvolvidos na sala de aula e a busca de um ensino contextualizado e voltado para a formação da cidadania do aluno.

Sempre que possível, faz-se uso de temas geradores, relacionados com o dia-adia do aluno, com o intuito de criar um elo entre o cotidiano e o conteúdo programáti$\mathrm{co}$, de forma que o estudante encontre respostas para as questões presentes fora da escola. Assim, o professor tem a possibilidade de desfazer o mito de que o ensino acadêmico não apresenta utilidade para o adolescente.

Sendo a educação para a cidadania a 
e-Mosaicos - Revista Multidisciplinar de Ensino, Pesquisa, Extensão e Cultura do Instituto de Aplicação Fernando Rodrigues da Silveira (CAp-UERJ)

ANO 1 - V. 1 - N. 1 - JUNHO 2012 - ISSN: 2316-9303

função primordial do ensino básico, serão abordadas questões que propiciem a discussão crítica da influência da química na sociedade tecnológica atual.

$\mathrm{Na}$ busca por atividades que proporcionem a aprendizagem significativa, por parte dos alunos, optou-se por atividades que incitem o caráter investigativo e a capacidade de tomada de decisão, de forma que o aluno não seja um mero seguidor de roteiros, ou um observador de demonstrações, mas que participe ativamente do planejamento e execução das tarefas, formule hipóteses, discuta os resultados e chegue a uma conclusão.

Sendo o CAp um espaço onde os alunos das diversas licenciaturas da UERJ desenvolvem seus estágios de prática de ensino, este projeto sempre esteve aberto para a participação dos licenciandos, de forma que este tenham contato com esta metodologia em sua formação inicial.

No tocante as aulas experimentais, priorizou-se o uso de materiais caseiros e de baixo custo. Além de aproximar a discussão para o cotidiano do aluno, esta ação minimiza o emprego de reagentes e equipamentos específicos, ampliando a viabilidade de aplicação desta metodologia para colégios que não possuam laboratórios, ou com restrições orçamentárias.

Enquanto as atividades experimentais encontram-se estabelecidas de forma sistemática no CAp/UERJ desde 1999, somente em 2003 deu-se início ao projeto de ensino de química mediado por computador. Devido a restrições de uso da sala de informática e ao estágio ainda incipiente de desenvolvimento de softwares educacionais de química para o ensino médio, o ponto de partida deste projeto foi a pesquisa de softwares existentes no mercado e disponíveis na rede mundial de computadores direcionados para o ensino de química. Assim, os softwares foram selecionados conforme as necessidades do currículo e integrados às atividades da sala de aula. Em seguida, partiu-se para o desenvolvimento de softwares que atendam aos interesses dos alunos e professores que atuam neste segmento de ensino.

\section{Análise dos questionários aplicados aos alunos}

Um dos principais objetivos deste projeto foi a contextualização das atividades. Ao se verificar os dados apresentados na Tabela 1, pode-se constatar que, em todos os anos pesquisados, a maioria dos alunos considerou que as aulas práticas facilitaram a correlação entre os conceitos químicos e seu dia-a-dia.

Tabela 1 - Percentual de alunos que consideraram que as aulas práticas facilitaram a compreensão de seu cotidiano.

\begin{tabular}{c|c}
\hline Ano da avaliação & Percentual de alunos (\%) \\
\hline 1 & 83,5 \\
2 & 77,4 \\
3 & 66,7 \\
\hline
\end{tabular}

Esta tendência de resposta também esteve presente nas opiniões dos alunos:

"Nas aulas de laboratório nós aprendemos coisas que fazem parte do nosso dia-a-dia e isso é muito importante."

"Através das aulas de laborató- 
e-Mosaicos - Revista Multidisciplinar de Ensino, Pesquisa, Extensão e Cultura do Instituto de Aplicação Fernando Rodrigues da Silveira (CAp-UERJ) ANO 1 - V. 1 - N. 1 - JUNHO 2012 - ISSN: 2316-9303

rio, podemos conhecer mais as coisas com que convivemos. Adorei todas as práticas realizadas, o que me ajudou muito a entender melhor as coisas."

"Conseguem fazer com que se perceba a utilização da química no cotidiano."

"Desperta o interesse do aluno sobre a química, facilitando o entendimento de vários processos químicos do dia-a-dia."

"Nestes três longos anos elas me ajudaram a entender os fenômenos químicos presentes ao meu redor."

"Pode se entender o mundo a sua volta através de uma visão química."

"Pode-se destacar como ponto positivo a proximidade do conteúdo passado na sala com a nossa realidade no nosso cotidiano, mostrando que o que se passa na aula realmente existe."

Desta análise, pode-se constatar a importância que os alunos atribuem ao saber escolar, quando este é apresentado como um saber mediador, que surge da interação entre os saberes existentes e novas formas de saber (Silva e Zanon, 2000). Cardoso e Colinvaux (2000) compartilham esta ideia e afirmaram que ao se vincular o ensino de química aos conhecimentos e conceitos presentes no cotidiano do aluno, consegue-se justificar e motivar o ensino desta disciplina, rompendo a barreira existente entre o conhecimento escolar e o social. Dentro desta linha de raciocínio, Santos e Schnetzler (1996), defendem um ensino de química para formar o cidadão, onde é imprescindível a vinculação do conteúdo trabalhado em sala de aula com o contexto social em que o aluno está inserido.

Desde a implantação do projeto, os alunos demonstram grande interesse e participação nas aulas práticas, o que evidenciou o papel motivador do experimento no processo de aprendizagem. No terceiro ano da pesquisa, acrescentou-se uma pergunta ao questionário, visando avaliar a motivação despertada por esta atividade. Dos alunos avaliados, 78,6 \% responderam que esta atividade contribuiu para motivá-los.

A importância dos fatores afetivos e emocionais no processo de construção do conhecimento foi apontada por Santos (1997), que destacou: "a aprendizagem é uma mudança conceitual sob a perspectiva emocional". Esta autora resgatou os estudos de Vygotsky, ao observar que o pensamento tem origem no âmbito da motivação e inclui necessidades, interesses, impulsos, afetos e emoções. Assim, "são os gostos e desgostos que vão estruturando e reestruturando nossas relações com o mundo circundante".

Ao se analisar os relatos e opiniões dos alunos, um aspecto muito destacado foi a interação dinâmica inerente às aulas práticas, onde, ao executarem papéis, os adolescentes se sentem parte fundamental no processo de construção do conhecimento. Algumas opiniões que colaboram para esta consideração são:

"As aulas de laboratório, além de serem descontraídas e fugirem da rotina do cotidiano escolar, ajudam-nos a compreender melhor o conteúdo dado em sala de aula."

"As aulas de laboratório têm como ponto positivo tornar as 
e-Mosaicos - Revista Multidisciplinar de Ensino, Pesquisa, Extensão e Cultura do Instituto de Aplicação Fernando Rodrigues da Silveira (CAp-UERJ)

ANO 1 - V. 1 - N. 1 - JUNHO 2012 - ISSN: 2316-9303

aulas mais dinâmicas, e que não fiquem rotineiras."

"É mais interessante ver a química pelo lado prático, fazendo experiências."

"Nós alunos podemos participar ativamente do que é feito."

"Todos participam de alguma forma, o que prende a atenção do aluno."

"Ela (aula prática) sai da rotina fazendo que o ensino seja mais interativo."

Borges (1997) colabora para esta linha de pensamento, destacando o caráter informal do laboratório, em contraposição à formalidade das demais aulas. Entretanto, deve-se ter ciência que os alunos costumam creditar como o ponto mais atrativo do emprego das aulas práticas o fato de que no laboratório estes estão mais ativos, no sen- tido de estarem "fazendo algo", mas muitas vezes estes não conseguem estabelecer uma relação entre o que está sendo feito e o que está sendo aprendido.

A maior participação dos alunos também contribuiu de forma positiva na socialização das atividades. Tendo em vista que o desenvolvimento das atividades foi realizado em pequenos grupos, tornou-se possível buscar condições que propiciassem a aprendizagem colaborativa, ressaltando o espírito de trabalho em equipe.

Com o intuito de avaliar a aceitação do programa de aulas experimentais, foi perguntada sua opinião sobre a manutenção destas atividades. Conforme pode-se analisar das respostas apresentadas na Tabela 2, em todos os momentos de avaliação, a maioria dos alunos, além de considerar que as que as atividades de laboratório deveriam ser mantidas, solicitou a ampliação do número de aulas práticas ao longo do ano letivo.

Tabela 2 - Opinião dos alunos sobre o número de aulas práticas no ano letivo.

\begin{tabular}{|c|c|c|c|c|}
\hline \multirow{2}{*}{$\begin{array}{c}\text { Ano da } \\
\text { Avaliação }\end{array}$} & \multicolumn{4}{|c|}{ Percentual de alunos que consideram que as aulas práticas devem ser: } \\
& mantidas & $\begin{array}{c}\text { mantidas e } \\
\text { ampliadas }\end{array}$ & $\begin{array}{c}\text { mantidas, mas em } \\
\text { número reduzido }\end{array}$ & canceladas \\
\hline 1 & 19,9 & 78,5 & - & 1,6 \\
\hline 2 & 22,6 & 74,0 & - & 3,4 \\
\hline 3 & 17,9 & 78,5 & 0,6 & 3,0 \\
\hline
\end{tabular}

Visando avaliar as atividades de informática, as quatro turmas de segunda série do ensino médio do CAp-UERJ participaram de três aulas de titulação ácido $x$ base: na sala de aula, no laboratório de química e no laboratório de informática. Após as aulas, os alunos tiveram a oportunidade de avaliar e comparar os procedimentos.

Verificou-se que $95 \%$ dos alunos aprovaram as atividades no laboratório de informática e citaram que o software foi uma 
ferramenta motivadora para uma melhor compreensão do procedimento experimental e de sua utilidade. Contudo, $32 \%$ dos alunos mencionaram preferir o trabalho experimental no laboratório de Química em detrimento do uso do computador, em função de poderem realizar os experimentos com substâncias reais e visualizarem melhor o fenômeno.
Quando questionados se o software proporcionou uma boa simulação do procedimento no laboratório de química, $92 \%$ dos alunos afirmaram que a simulação reproduziu o experimento, conforme apresentado no gráfico da Figura 1. Apesar desta aprovação, alguns alunos comentaram sobre a necessidade de algumas melhorias, tais como imagens em três dimensões.

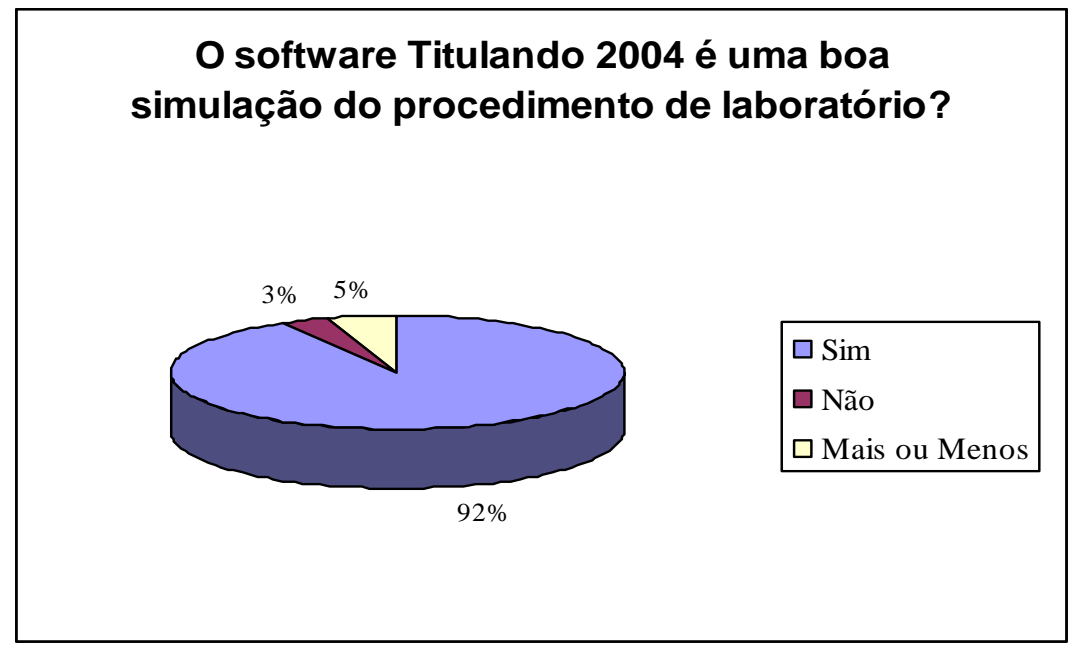

Figura 1 - Avaliação dos alunos sobre a eficiência da simulação da titulação.

Ao se perguntar aos alunos sobre quais os espaços mais os agradaram, verificou-se que $43 \%$ destes preferiram as atividades de laboratório e de informática e $20 \%$ preferiram apenas a informática. Contudo, $32 \%$ do alunos mencionaram preferir o trabalho experimental no laboratório de Química, em detrimento do uso do computador, para poderem realizar os experimentos com substâncias reais e visualizarem melhor o fenômeno. Estes resultados estão representados no gráfico da Figura 2 . 


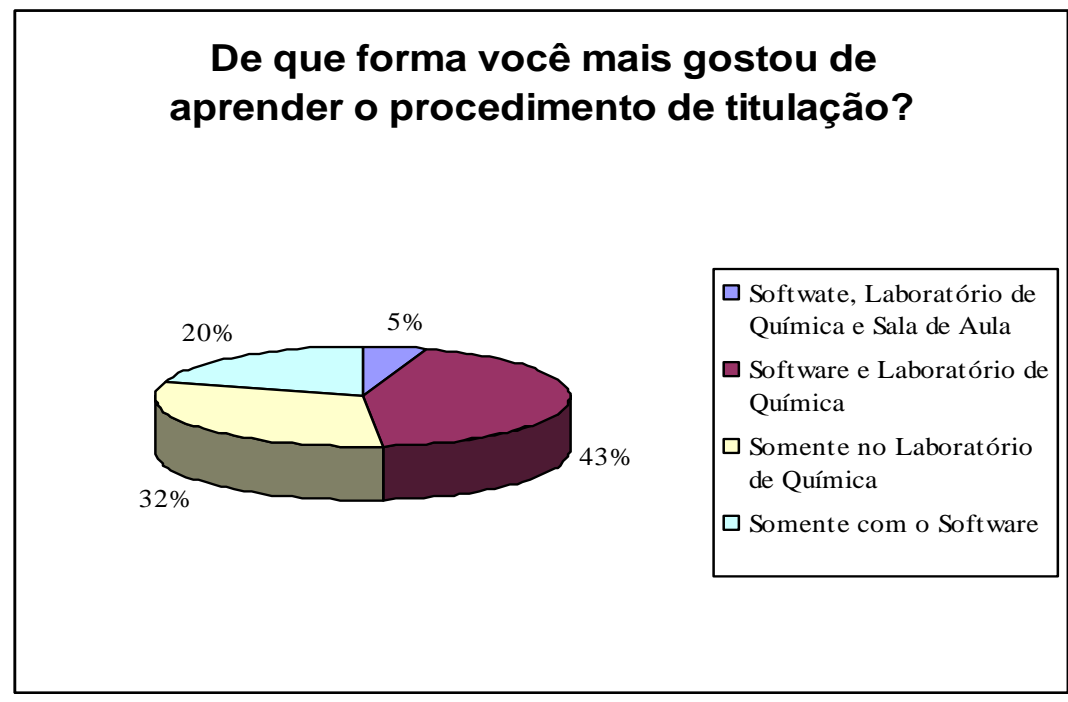

Figura 2 - Resultados da comparação entre três aulas de titulação: Laboratório de Química x Simulação x Sala de Aula.

\section{CONCLUSÕES}

As aulas práticas e de informática demonstraram-se um recurso didático importante para o ensino de química. O desenvolvimento destas atividades proporcionou grande motivação dos alunos, o que foi constatado pelo aumento da participação destes nas atividades. Além disto, o experimento favoreceu a construção do conhecimento, estimulando o caráter investigativo, a tomada de decisão e a aprendizagem colaborativa.

A contextualização das atividades possibilitou a discussão das questões que envolvem a relação entre ciência, tecnologia e sociedade no mundo moderno, colaborando para a formação de um cidadão crítico.

A aplicação de softwares educativos, em turmas de química da educação básica, demonstrou que sua inserção na prática pedagógica, inclusive em conjunto com as aulas experimentais, favorece a motivação dos alunos, torna as aulas mais dinâmicas e agradáveis e contribui para o processo de construção do conhecimento.

O presente projeto colaborou para a valorização do CAp/UERJ como espaço concebido para a criação e aplicação de novas teorias e/ou metodologias. Por suas características particulares dentro da Universidade, o CAp é um local que permite a integração da teoria de educação em química com a prática pedagógica. Como o CAp é o campo de estágio para alunos de licenciatura, este projeto irá estender, aos futuros professores, esta metodologia alternativa, cumprindo assim sua função social.

\section{REFERÊNCIAS BIBLIOGRÁFICAS}

Almeida, M. J. P. M. e Barreto Filho, B. B. Um diálogo com trabalhos sobre experimentação nas ciências do ensino fundamental. Atas do II Encontro Nacional de Pesquisa em Ensino de Ciências, Atibaia, 2001.

Brasil. Lei de Diretrizes e Bases da Educação 
e-Mosaicos - Revista Multidisciplinar de Ensino, Pesquisa, Extensão e Cultura do Instituto de Aplicação Fernando Rodrigues da Silveira (CAp-UERJ) ANO 1 - V. 1 - N. 1 - JUNHO 2012 - ISSN: 2316-9303

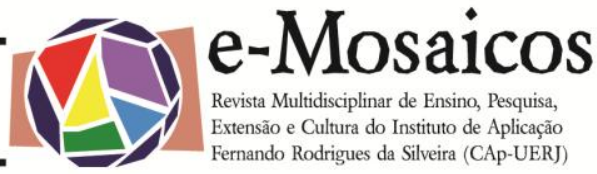

Nacional. Lei no 9.394, de 20 de dezembro de 1996.

Borges, A. T. O papel do laboratório no ensino de ciências. In: Atas do I Encontro Nacional de Pesquisa em Ensino de Ciências, p. 2-11, Águas de Lindóia, 1997.

Brito, S. L. Um ambiente multimediatizado para a construção do conhecimento em química. Química Nova na Escola, n. 14, p. 13-15, 2001.

Cardoso, S. P. e Colinvaux, D. Explorando a motivação para estudar química. Química Nova, v. 23, n. 3, p. 401-404, 2000.

Dallacosta, A., Fernandes, A. M. R. e Bastos, R. C. Desenvolvimento de um software educacional para o ensino de química relativo à tabela periódica, IV Congresso RIBIE, Brasilia 1998. Disponível em: $<$ http://www.c5.cl/ieinvestiga/actas/ribie98/ 160.html > Acesso em 12 ago. 2003.

Eichler, M. e Del Pino, J. C. Modelagem e implementação de ambientes virtuais de aprendizagem em ciências, IV Congresso RIBIE, Brasília, 1988. Disponível em: $<$ http://www.C5.cl/ieinvestiga/actas/ribie98/ 129.html > Acesso em 12 ago. 2003.

Eichler, M. e Del Pino, J. C. Jornais e revistas on-line. Química Nova na Escola, n. 9, p. 6-8, 1999.

Eichler, M. e Del Pino, J. C. Carbópolis, um software para educação química. Química Nova na Escola, n. 11, p. 10-12, 2000a.

Eichler, M. e Del Pino, J. C. Computadores em Educação Química: Estrutura Atômica e Tabela Periódica, Química Nova, v. 23, n. 6. p. $835-840,2000$ b.

Giordan, M. O papel da experimentação no ensino de ciências. Química Nova na Escola, n. 10, p. 43-49, 1999.

Giordan, M. e Mello, I. C. Educação aberta na web. Química Nova na Escola, n. 10, p. 8-10, 2000.

Lôbo, S. F. e Moradillo, E. F. Epistemologia e a formação docente em química. Química Nova na Escola, n. 17, p. 39-41, 2003.

Machado, A. H. Aula de Química: discurso e conhecimento. Ijuí, Editora Unijuí, 1999.

Meleiro, A. e Giordan, M. Hipermídia no ensino de modelos atômicos. Química Nova na Escola, n. 10, p. 14-16, 1999.

Michel, R., Santos, F. M. T. e Greca, I. M. R. Uma busca na Internet por ferramentas pra a educação química no ensino médio. Química Nova na Escola, n. 10, p. 3-7, 2004.

Mortimer, E. F. e Carvalho, A. M. P. Referenciais teóricos para análise do processo de ensino de ciências. Cadernos de Pesquisas, n. 96, p. 5-14, 1996.

Mortimer, E. F., Machado, A. H. e Romaneli, L. I. A proposta curricular de química do estado de Minas Gerais: fundamentos e pressupostos. Química Nova, v. 23, n. 2, p. 273-283, 2000.

Santos, W. L. P. e Schnetzler, R. P. Função social. $O$ que significa ensino de química para formar o cidadão? Química Nova na Escola, n. 4, p. 28-34, 1996.

Schnetzler, R. P. A pesquisa em ensino de química no Brasil: conquistas e perspectivas, Química Nova, v. 25, n. 1, p. 14-24, 2002.

Silva, L. H. A. e Zanon, L. B. A experimentação no ensino de ciências. In: Schnetzler, R. P. e Aragão, R. M. R. (org.) Ensino de Ciências: Fundamentos e Abordagens. Campinas: R. Vieira Gráfica e Editora Ltda., 2000.

Souza, M. P., Merçon, F., Santos, N., RapelIo, C. N. e Sgarbi A. C. Desenvolvimento e Aplicação de um Software como Ferramenta Motivadora no Processo EnsinoAprendizagem de Química. In: SBIE 2004 - 
e-Mosaicos - Revista Multidisciplinar de Ensino, Pesquisa, Extensão e Cultura do Instituto de Aplicação Fernando Rodrigues da Silveira (CAp-UERJ)

ANO 1 - V. 1 - N. 1 - JUNHO 2012 - ISSN: 2316-9303

\section{Simpósio Brasileiro de Informática na} Educação, Manaus, nov. 2004.

Vieira, S. L. Contribuições e limitações da Informática para a Educação Química. QMCWEB, Ano 2, n. 45, Florianópolis, 2001, disponível em: $<$ http://www.amc.ufsc.br/qmcweb/artigos/c olaboracoes/informatica ensino.html> Acesso em: 10 ago. 2003.

${ }^{1}$ mercon@uerj.br - Graduado em Engenharia Química (1991) e Licenciatura em Química (1994) pela Universidade do Estado do Rio de Janeiro e Mestrado (1994) e Doutorado (1998) em Engenharia Química pela Universidade Federal do Rio de Janeiro. Atualmente é Professor Adjunto da Universidade do Estado do Rio de Janeiro / Instituto de Aplicação Fernando Rodrigues da Silveira - CAp-UERJ, estando vinculado ao Programa de Pós-Graduação em Química. Tem experiência nas áreas de Ensino de Química, Química Ambiental e Processos com Membranas.

2 secdeptos.capuerj@gmail.com - Graduado em Engenharia Química (1991), Licenciatura em Química (1994) e Bacharelado em Informática (2003) pela Universidade do Estado do Rio de Janeiro. Possui Mestrado em Engenharia Química pela Universidade Federal do Rio de Janeiro (1997). Atualmente é Professor Assistente da Universidade do Estado do Rio de Janeiro / Instituto de Aplicação Fernando Rodrigues da Silveira - CAp-UERJ e professor e coordenador de disciplina do Colégio Andrews. Tem experiência na área de Educação, com ênfase em Tecnologia Educacional, atuando principalmente nos seguintes temas: ensino de química, informática no ensino de química, meio ambiente, desenvolvimento de software.

3 post mortem

${ }^{4}$ secdeptos.capuerj@gmail.com - Licenciado em Química pela Universidade Federal do Rio de Janeiro (1984), Graduação em Pedagogia - Ficab (1987), Graduação em Direito pela Universidade
Gama Filho (1994), Mestrado em Direito (área de concentração Estado e Cidadania) pela Universidade Gama Filho (2000) e Doutorado em Serviço Social pela Universidade do Estado do Rio de Janeiro (2009). Atualmente é Professor Adjunto da Universidade do Estado do Rio de Janeiro / Instituto de Aplicação Fernando Rodrigues da Silveira - CAp-UERJ, atuando principalmente nos seguintes temas: educação, cidadania, cotas nas universidades públicas, legislação e inclusão social, sustentabilidade e meio ambiente.

${ }^{5}$ secdeptos.capuerj@gmail.com - Licenciada em Química pela Universidade do Estado do Rio de Janeiro e Especialização em Desempenho Escolar pela Faculdade de Humanidades Pedro II(1995). Atualmente é Professora Auxiliar da Universidade do Estado do Rio de Janeiro / Instituto de Aplicação Fernando Rodrigues da Silveira - CAp-UERJ e Professora do Colégio Pedro II.

6 secdeptos.capuerj@gmail.com - Licenciado pela Fundação Técnico Educacional Souza Marques (1978) e Graduado em Química Industrial pela Fundação Técnico Educacional Souza Marques(1979). Atualmente leciona na Universidade do Estado do Rio de Janeiro / Instituto de Aplicação Fernando Rodrigues da Silveira - CApUERJ. 